\title{
Review
}

Complications

Diabetes Metab J 2014;38:163-170

http://dx.doi.org/10.4093/dmj.2014.38.3.163

pISSN 2233-6079 • eISSN 2233-6087

DIABET\&S \& M ETABOLISM JOURNAL

\section{Interrelationships between the Retinal Neuroglia and Vasculature in Diabetes}

\author{
Timothy S. Kern ${ }^{1,2}$ \\ ${ }^{1}$ Department of Medicine, Case Western Reserve University Medicine, Cleveland, OH; \\ ${ }^{2}$ Department of Medicine, Louis Stokes Cleveland Veterans Administration Medical Center, Cleveland, OH, USA
}

For years, diabetic retinopathy has been defined based on vascular lesions, and neural abnormalities were not regarded as important. This review summarizes evidence that the neural retina has important effects on the retinal vasculature under normal conditions, and the interaction between the retinal neuroglial cells and vascular function is altered in diabetes. Importantly, new evidence raises a possibility that abnormalities within retinal neuroglial cells (notably photoreceptors) might actually be causing or initiating the vascular disease in diabetic retinopathy.

Keywords: Diabetes mellitus; Diabetic retinopathy; Neurovascular coupling; Photoreceptors; Retina

\section{INTRODUCTION}

Under normal conditions, neurons, glia, and vasculature of the brain or retina act together in a coordinated manner. Cells constantly are bathed in chemical moderators, hormones, ions, and proteins from surrounding cells and tissues, and these signals coordinate a local interrelationship between metabolism, capillary density, and blood flow. Notably, changes in neuronal activity induce changes in vascular blood flow and density.

The purpose of this review is to summarize data indicating that the interaction between neural and vascular cells becomes altered in retina in diabetes, and to provide new evidence that suggests that neural cells of the retina can contribute to the development of vascular alterations that are characteristic of the early stages of diabetic retinopathy.

\section{NEUROVASCULAR COUPLING}

Neurovascular coupling refers to the relationship between lo- cal neural activity and changes in blood flow. Thus, this describes a process in which neural tissue regulates its blood flow in response to neural activity.

In the retina, there is significant linkage between neural activity of retinal ganglion cells (or at least inner retina) and blood flow [1-4]. The retina has unique sensitivity to light, and the response of the retinal vasculature to light-induced changes in neural function has provided considerable insight into neurovascular coupling in the retina [4]. Human and animal studies have indicated that retinal or photoreceptor oxygen consumption is greater in dark than light, yet oxygen saturation in retinal blood vessels is higher in dark than in light [5]. Moreover, velocity of blood in the retinal vessels is increased at night [6]. The increased delivery of oxygen in response to the increased activity of retinal neurons is a consequence of the coupling between neural activity and the vasculature. Since the blood vessels do not directly respond to light, lightinduced changes in blood flow or oxygen delivery must be initiated by light-induced changes in neural activity of the retina. Surprisingly, dark adaptation did not increase retinal blood
Corresponding author: Timothy S. Kern

Department of Medicine, Case Western Reserve University Medicine, 441

Wood Building, Case Western Reserve University, 10900 Euclid Ave,

Cleveland, OH 44106, USA

E-mail: tsk@case.edu.
This is an Open Access article distributed under the terms of the Creative Commons Attribution Non-Commercial License (http://creativecommons.org/licenses/by-nc/3.0/) which permits unrestricted non-commercial use, distribution, and reproduction in any medium, provided the original work is properly cited. 
flow in Sprague-Dawley rats.

Flicker light stimulation further demonstrates neurovascular coupling in the retina. Various animal and human studies have demonstrated that retinal and optic nerve blood flow increase in response to diffuse luminance flicker (light on, light off) [7]. Diffuse luminance flicker stimulation increased optic nerve-head blood flow markedly in anesthetized cats, and the increase depended upon the intensity, frequency, and wavelength of the stimulation and the state of adaptation of the retina [8]. Blood flow around the macula, as assessed by blue field simulation technique in normal subjects, also increases in response to diffuse luminance flicker [9]. Investigators have reported that flicker light-induced vasodilation was mediated by ganglion cells [4] or pericytes [10]. There is significant correlation between neural activity of retinal ganglion cells and enhanced glucose delivery and metabolism during light flicker [11].

\section{Neurovascular communication}

Possible mechanisms by which neuroglial cells communicate with vascular cells have been investigated. Some of these signaling molecules act rapidly (such as $\mathrm{H}^{+}, \mathrm{K}^{+}$, neurotransmitters, adenosine, arachidonic acid metabolites, and nitric oxide [NO]), whereas others seem to have a more prolonged effect (such as growth factors) $[4,12,13]$. It seems clear that the control of microcirculation by neuroglia is a complex process that likely involves a number of different molecules [14]. Some of these molecules are listed here.

1) NO can be made by every retinal cell type, and it is an important signaling molecule that regulates neurotransmitters release and modulates gap junction conductivity in retina. In the retina, the NO produced by the constitutive nitric oxide synthases (NOSs; endothelial NOS and neuronal NOS) contribute to regulate normal ocular hemodynamics and cell viability, and to protect retinal cells against different stresses $[15,16]$. Pretreatment of animals with a NO inhibitor inhibited the flicker-induced increase in retinal blood flow [17], indicating that NO plays an important role in the coupling between retinal neuronal activity and blood flow.

2) Metea and Newman [18] demonstrated that retinal glial cells mediate neurovascular coupling by inducing the production of two arachidonic acid metabolites, epoxyeicosatrienoic acids, and 20-hydroxyeicosatetraenoic acid, which dilate and constrict vessels, respectively. They showed that 1 ) light or direct glial stimulation produce vasodilatation or vasoconstric- tion mediated by these small molecules, 2) the vascular response depends on NO, and 3) glial cells are necessary for signaling from neurons to blood vessels.

3) Studies have demonstrated that a large fraction of neurovascular coupling that causes hyperemia is due to release of glutamate from neural tissue [19].

4) Vascular endothelial growth factor (VEGF) is another soluble factor that couples neuroglia and the vasculature. VEGF is produced largely by glia and neurons. It is known to have important effects on vascular development, permeability and, in ischemic diseases, also neovascularization [20].

5) Neurotrophins are another way by which neural tissue might communicate with the retinal vasculature. The neurotrophins are a family of trophic factors (including nerve growth factor [NGF], brain-derived neurotrophic factor, neurotrophin-3, and neurotrophin-4/5) which promote neural cell survival, neurite outgrowth, phenotypic maturation, and synaptic functioning, but also exert a trophic effect on some, but perhaps not all, endothelial cells. Endothelial cells from the brain, dermis, and umbilical vein have been reported to contain the NGF receptors TrkA and p75NGFR, and to respond to NGF with cell mitosis, migration, and survival. Cerebral endothelial cells, however, have been reported to not respond to NGF [21].

\section{NEUROVASCULAR INTERACTIONS AND DISEASE}

Alterations in neurovascular coupling and cerebrovascular regulation have been proposed to play a key role in the process of ageing as well as in stroke, hyperlipidemia, hypertension, and diabetes. This review will now focus on alterations in neurovascular interactions in diabetes.

\section{Regulation of retinal blood flow by neural activity in diabetes}

Whereas a variety of studies describe the effects of flickering light on retinal and optic nerve head blood flow under normal conditions, the knowledge about this coupling in the diabetic retina is less complete. Nevertheless, available evidence indicates that neurovascular coupling in the retina is altered in diabetes. Luu et al. [22] demonstrated that a component of the neural oscillatory potential of the electroretinogram (ERG) correlated with retinal arteriolar caliber in patients with diabetes, demonstrating at least a correlation between retinal neuronal dysfunction and blood flow. Flicker responses of retinal 
arteries and veins in insulin-dependent diabetic patients [23] and in healthy subjects made experimentally hyperglycemic [24] have shown significant reduction compared to controls. The flicker-induced retinal diameter change has been shown to deteriorate early in patients with diabetes; Lecleire-Collet et al. [25] found a significant reduction of the flicker-induced response in the retinal arteries and veins of normotensive patients with diabetes with no clinically detectable diabetic retinopathy. Nguyen et al. [26] showed that reduced retinal vasodilation after flicker light stimulation was associated with diabetes, independent of major risk factors such as hypertension and glycemic control. Whether or not there is a difference between type 1 diabetes and type 2 is not clear; a controlled study demonstrated decreases in both arterial and venous flicker-induced retinal vasodilation in normotensive patients with type 1 diabetes and no diabetic retinopathy [27], whereas an uncontrolled study of patients with type 2 diabetes by the same research group [28] demonstrated that the observed decreases in the arterial and venous flicker-induced responses were no longer significant after factoring out age and antihypertensive treatment.

The impaired flicker-induced vascular response may be partly caused by endothelial dysfunction, as suggested by Mandecka et al. [27,28] and Nguyen et al. [26,29]. A key role for NO has been identified in retinal and optic nerve vasodilatory response to greater neuronal activity. Light-evoked arteriole dilation (functional hyperemia) is reduced diabetic rats, and inhibition of iNOS restored both light- and glial-evoked dilation of retinal arterioles to control levels [30].

\section{Diabetic retinopathy}

Diabetic retinopathy is a common complication of diabetes and a leading cause of legal blindness among working-age adults. Historically, diabetic retinopathy researchers and physicians have concentrated on the vascular lesions in this disease, since those are what seem to account for most of the lesions that contribute to vision loss in diabetes. It is now clear that the neuronal components of the retina are also injured in diabetes, and appear to become impaired prior to the regression of the retinal vasculature. We will first present a brief summary of diabetic retinopathy, and then summarize recent evidence that neural abnormalities within the retina are actually contributing to the vascular lesions of the retinopathy.

\section{Vasculature}

Diabetic retinopathy is comprised of a spectrum of histologic and functional abnormalities that in composite make a picture that is relatively unique for diabetes. These abnormalities include nonperfused and degenerate capillaries, pericyte ghosts (empty pockets in the basement membrane surrounding capillaries where pericytes used to be located), microaneurysms, increased vascular permeability, and intraretinal microvascular abnormalities in early stages of the disease. In the advanced (clinically important) stages of the retinopathy, hemorrhage, retinal edema, neovascularization, and possibly retinal detachment occur.

\section{Neurons}

Some nonvascular cells, likely retinal ganglion cells, begin to degenerate (become positive for terminal deoxynucleotidyl transferase dUTP nick-end labeling stain (TUNEL) early in diabetes, and in fact some retinal neurons apparently begin to degenerate earlier than do vascular cells [31-33]. Retinal crosssections or in vivo measurements from diabetic rodents or patients have revealed retinal thinning in diabetes [33], which also is consistent with neuronal death. Although some neuroglial cells do die in diabetes, even greater numbers of cells likely survive but become dysfunctional.

Diabetes-induced retinal dysfunction has been well documented. In the retinas of human diabetics, pattern ERGs become diminished before the onset of the classically defined nonproliferative retinopathy [34,35], and delayed physiological signals (evoked potentials) have been found in the optic nerve (axons of the retinal ganglion cells) and visual pathways of diabetic patients. A recent study of early diabetes indicated that patients having nonproliferative diabetic retinopathy showed impairment of visual function compared to normal participants, with $83 \%$ of patients exhibiting clinically significant impairment [36]. In addition, rod photoreceptor function was grossly impaired. Contrast sensitivity and other defects in vision have been widely studied in patients with diabetic retinopathy. Trick et al. [37] found that about one-third of diabetic subjects without retinopathy had abnormalities in contrast sensitivity, this figure rising to about two-thirds in those with nonproliferative (background) retinopathy. These electrophysiological measures provide indications of functional changes in neural cells of the retina in the earliest stages of human diabetic retinopathy.

Retinal levels of NO, glutamate, VEGF and neurotrophins 
are altered in diabetic retinopathy.

\section{1) Nitric oxide}

It is clear from multiple investigations that NO levels are altered in diabetes. Increased serum levels of nitrite and nitrate (breakdown products of NO) have been found in diabetic patients with retinopathy compared with diabetic patients without diabetic retinopathy or healthy controls. In those studies, serum nitrite and nitrate (used to estimate NO) levels in the patients with proliferative diabetic retinopathy were significantly higher than the levels in the patients with nonproliferative retinopathy. Likewise, plasma nitrite and nitrate levels were higher in patients with proliferative diabetic retinopathy than in controls also in other studies. Elevated metabolites of the L-arginine-NO pathway have been detected also in the vitreous of eyes from diabetic patients, and greater than normal levels of NG-hydroxy-L-arginine (a by-product of NO generation), have been detected in the ocular aqueous humor of diabetic patients (with and without diabetic retinopathy) compared with that in nondiabetic controls. Despite what appears to be increased generation of NO in diabetes; however, diabetes results in subnormal NO bioavailability, due to increased production of free radicals which directly react with $\mathrm{NO}$ to generated peroxynitrite, or oxidize the cofactors of the NO synthase, diminishing the activity of NO synthases and consequently leading to a decreased NO production [38].

\section{2) Glutamate}

In diabetes, levels of the excitotoxin, glutamate, have been reported to be significantly increased [39] or decreased [40] in retinas of diabetic rodents. In diabetic patients, levels of glutamate in the vitreous are significantly elevated [41,42]. The increase in retinal glutamate in diabetic rodents was inhibited with systemic administration of antioxidants [39].

\section{3) VEGF}

Levels of VEGF in retina and vitreous are elevated in diabetes, and there is strong evidence that this VEGF increases vascular permeability and neovascularization in advanced diabetic retinopathy $[43,44]$. In vitro, VEGF plays a critical role in endothelial cell apoptosis induced by high glucose [45]. In vivo, Bai et al. [46] demonstrated that disruption of Müller cell-derived VEGF resulted in significant inhibition of the ischemia-induced retinal neovascularization and vascular leakage, and attenuation of the ischemia-induced breakdown of the blood- retina barrier.

\section{4) Neurotrophins}

Systemic administration of NGF to diabetic animals inhibits diabetes-induced vascular degeneration in the retina [47]. This benefit of NGF administration might not be mediated by a direct effect on the endothelium itself, but rather an indirect effect on other members of the neurovascular components in the retina, because retinal endothelial cells have been reported not respond to NGF in vitro [48]. The observed beneficial effect of NGF on the retinal vasculature in diabetes might indicate a diabetes-induced defect in neurovascular communication that can be corrected therapeutically. Diabetes-induced impairment of NGF processing leads to accumulation of proNGF, which has been postulated to contribute to development of diabetic retinopathy [49].

\section{NEW EVIDENCE SUGGESTING THAT RETINAL NEURONS CONTRIBUTE TO VASCULAR DISEASE IN DIABETIC RETINOPATHY}

The finding that retinal neurons (especially ganglion cells) began dying (estimated from TUNEL staining) before vascular lesions were grossly apparent led some investigators to speculate that neurons might contribute to the development of the vascular lesions of diabetic retinopathy [31]. No evidence to support this postulate was identified until recently, when retinal photoreceptors were identified as likely contributors to the vascular damage in the retinopathy.

Photoreceptors are specialized retinal neurons, and mediate the capture of light energy and conversion of that light into neural signals that allow us to see. The high metabolic rate of photoreceptors has been recognized as contributing to development of retinal hypoxia and subsequently neovascularization in late, advanced stages of diabetic retinopathy, but recent reports have raised a possibility that photoreceptors or outer retina might play a role in the development also of even early stages of diabetic retinopathy. de Gooyer and collaborators [50] reported that diabetes did not cause the expected decrease in density of the retinal microvasculature in mice lacking rhodopsin $\left(\mathrm{Rho}^{-1}\right.$, which causes photoreceptor degeneration). The authors concluded that loss of the outer retina reduced the severity of diabetic retinopathy in that model. Two additional pieces of data involving diabetic patients are consis- 
tent with a role of photoreceptors in the development of diabetic retinopathy. Results of a survey sent to a small group of diabetic patients who also had retinitis pigmentosa (and therefore, photoreceptor degeneration) suggested that diabetic retinopathy was less severe in patients who also had retinitis pigmentosa [51]. In addition, Arden et al. [52,53] conducted a study on patients to determine if sleeping without total darkness (to reduce the dark current in rod photoreceptors) could improve diabetes-induced abnormalities of retinal function or structure, and found that the avoidance of total darkness significantly reduced the tritan thresholds, the area of dark retinal anomalies, and retinal edema in treated eyes relative to untreated eyes.

The mechanism by which neurons might contribute to vascular pathology of diabetic retinopathy will be important to determine. Perhaps impaired delivery of oxygen to photoreceptors at night and the resulting low oxygen levels in the retina, lead to increased levels of VEGF and its effects on the vasculature. In addition, recent studies demonstrate that photoreceptors generate (or at least regulate) generation of reactive oxygen species and synthesis of inflammatory proteins in the retina in diabetes [54]. This is important because diabetes results in increased generation of superoxide and inflammatory proteins in retina, and inhibition of the oxidative stress or de- letion/inhibition of inflammatory proteins has been shown to inhibit development of vascular lesions of early diabetic retinopathy $[55,56]$. Low intensity light is being found to inhibit aspects of diabetic retinopathy $[52,53,57]$, and offers a possible therapeutic direction for future efforts to inhibit the retinopathy.

\section{CONCLUSIONS}

Clinical evidence continues to support the premise that retinal vascular disease accounts for much of the clinically significant loss of vision that occurs in diabetes. However, neural function is an important regulator of normal vascular function, and disturbances in the interaction between neural and vascular cells can have adverse effects on retinal function or structure (Fig. 1). Intriguing new evidence indicates that photoreceptors and other neural cells might contribute to the pathogenesis of the vascular disease that is characteristic of diabetic retinopathy. Thus, therapeutic efforts to correct critical abnormalities within the retinal neuroglia might help inhibit both the vascular lesions that characterize diabetic retinopathy and the diabetes-induced loss of vision. Additional work is required to further investigate this possibility.

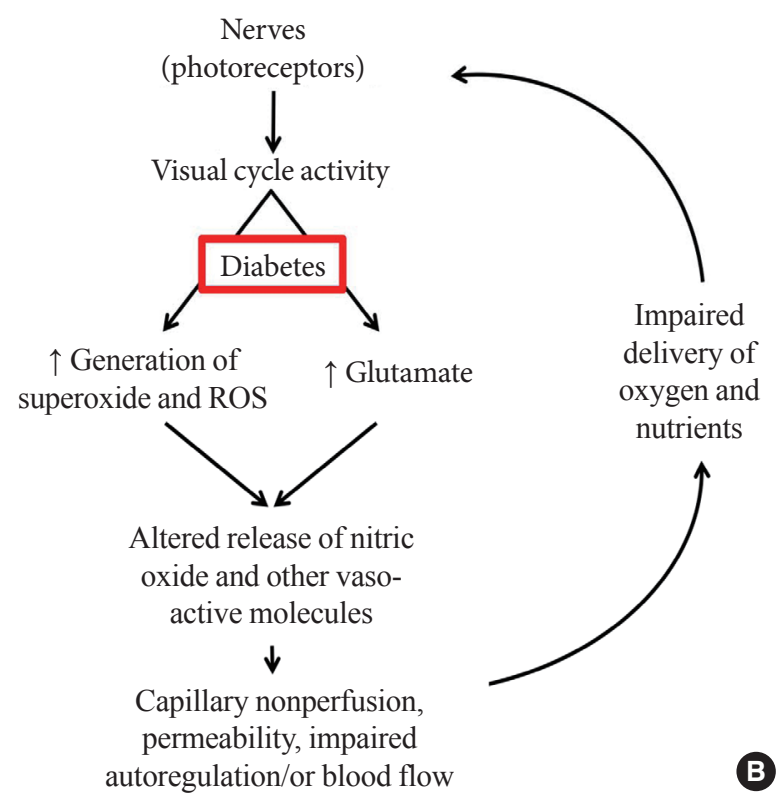

Fig. 1. Comparison of neural and vascular interactions in (A) nondiabetic and (B) diabetic conditions. Normally, neural metabolism influences blood delivery to neural tissues, and the increase in local blood flow after increased neural activity maintains the interaction between these two compartments. In diabetes, both neural signaling to the vasculature, and the delivery of nutrients to the retina become impaired. 


\section{CONFLICTS OF INTEREST}

This work was funded by PHS grants EY00300 and EY022938, and by a Merit grant from the Veteran's Administration.

\section{REFERENCES}

1. Buerk DG, Riva CE, Cranstoun SD. Frequency and luminancedependent blood flow and $\mathrm{K}+$ ion changes during flicker stimuli in cat optic nerve head. Invest Ophthalmol Vis Sci 1995; 36:2216-27.

2. Falsini B, Riva CE, Logean E. Flicker-evoked changes in human optic nerve blood flow: relationship with retinal neural activity. Invest Ophthalmol Vis Sci 2002;43:2309-16.

3. Logean E, Falsini B, Riva CE. Effect of chromatic flicker on circulation of the optic nerve. Klin Monbl Augenheilkd 2001;218: 345-7.

4. Riva CE, Logean E, Falsini B. Visually evoked hemodynamical response and assessment of neurovascular coupling in the optic nerve and retina. Prog Retin Eye Res 2005;24:183-215.

5. Hardarson SH, Basit S, Jonsdottir TE, Eysteinsson T, Halldorsson GH, Karlsson RA, Beach JM, Benediktsson JA, Stefansson E. Oxygen saturation in human retinal vessels is higher in dark than in light. Invest Ophthalmol Vis Sci 2009;50:2308-11.

6. Havelius U, Hansen F. Ocular vasodynamic changes in light and darkness in smokers. Invest Ophthalmol Vis Sci 2005;46: 1698-705.

7. Formaz F, Riva CE, Geiser M. Diffuse luminance flicker increases retinal vessel diameter in humans. Curr Eye Res 1997; 16:1252-7.

8. Riva CE, Harino S, Shonat RD, Petrig BL. Flicker evoked increase in optic nerve head blood flow in anesthetized cats. Neurosci Lett 1991;128:291-6.

9. Scheiner AJ, Riva CE, Kazahaya K, Petrig BL. Effect of flicker on macular blood flow assessed by the blue field simulation technique. Invest Ophthalmol Vis Sci 1994;35:3436-41.

10. Hamilton NB, Attwell D, Hall CN. Pericyte-mediated regulation of capillary diameter: a component of neurovascular coupling in health and disease. Front Neuroenergetics 2010;2;pii5.

11. Bill A, Sperber GO. Aspects of oxygen and glucose consumption in the retina: effects of high intraocular pressure and light. Graefes Arch Clin Exp Ophthalmol 1990;228:124-7.

12. Leybaert L. Neurobarrier coupling in the brain: a partner of neurovascular and neurometabolic coupling? J Cereb Blood Flow Metab 2005;25:2-16.
13. Iadecola C, Nedergaard M. Glial regulation of the cerebral microvasculature. Nat Neurosci 2007;10:1369-76.

14. Jakovcevic D, Harder DR. Role of astrocytes in matching blood flow to neuronal activity. Curr Top Dev Biol 2007;79:75-97.

15. Schmetterer L, Polak K. Role of nitric oxide in the control of ocular blood flow. Prog Retin Eye Res 2001;20:823-47.

16. Toda N, Nakanishi-Toda M. Nitric oxide: ocular blood flow, glaucoma, and diabetic retinopathy. Prog Retin Eye Res 2007; 26:205-38.

17. Kondo M, Wang L, Bill A. The role of nitric oxide in hyperaemic response to flicker in the retina and optic nerve in cats. Acta Ophthalmol Scand 1997;75:232-5.

18. Metea MR, Newman EA. Signalling within the neurovascular unit in the mammalian retina. Exp Physiol 2007;92:635-40.

19. Lauritzen M. Reading vascular changes in brain imaging: is dendritic calcium the key? Nat Rev Neurosci 2005;6:77-85.

20. Ferrara N, Gerber HP, LeCouter J. The biology of VEGF and its receptors. Nat Med 2003;9:669-76.

21. Ruprecht K, Stadelmann C, Hummel V, Klein O, Bruck W, Rieckmann P. Brain derived neurotrophic factor does not act on adult human cerebral endothelial cells. Neurosci Lett 2002; 330:175-8.

22. Luu CD, Szental JA, Lee SY, Lavanya R, Wong TY. Correlation between retinal oscillatory potentials and retinal vascular caliber in type 2 diabetes. Invest Ophthalmol Vis Sci 2010;51:482-6.

23. Garhofer G, Zawinka C, Resch H, Kothy P, Schmetterer L, Dorner GT. Reduced response of retinal vessel diameters to flicker stimulation in patients with diabetes. Br J Ophthalmol 2004;88:887-91.

24. Dorner GT, Garhofer G, Huemer KH, Riva CE, Wolzt M, Schmetterer L. Hyperglycemia affects flicker-induced vasodilation in the retina of healthy subjects. Vision Res 2003;43: 1495-500.

25. Lecleire-Collet A, Audo I, Aout M, Girmens JF, Sofroni R, Erginay A, Le Gargasson JF, Mohand-Said S, Meas T, Guillausseau PJ, Vicaut E, Paques M, Massin P. Evaluation of retinal function and flicker light-induced retinal vascular response in normotensive patients with diabetes without retinopathy. Invest Ophthalmol Vis Sci 2011;52:2861-7.

26. Nguyen TT, Kawasaki R, Wang JJ, Kreis AJ, Shaw J, Vilser W, Wong TY. Flicker light-induced retinal vasodilation in diabetes and diabetic retinopathy. Diabetes Care 2009;32:2075-80.

27. Mandecka A, Dawczynski J, Vilser W, Blum M, Muller N, Kloos C, Wolf G, Muller UA. Abnormal retinal autoregulation is detected by provoked stimulation with flicker light in well- 
controlled patients with type 1 diabetes without retinopathy. Diabetes Res Clin Pract 2009;86:51-5.

28. Mandecka A, Dawczynski J, Blum M, Muller N, Kloos C, Wolf G, Vilser W, Hoyer H, Muller UA. Influence of flickering light on the retinal vessels in diabetic patients. Diabetes Care 2007;30:3048-52.

29. Nguyen TT, Kawasaki R, Kreis AJ, Wang JJ, Shaw J, Vilser W, Wong TY. Correlation of light-flicker-induced retinal vasodilation and retinal vascular caliber measurements in diabetes. Invest Ophthalmol Vis Sci 2009;50:5609-13.

30. Mishra A, Newman EA. Inhibition of inducible nitric oxide synthase reverses the loss of functional hyperemia in diabetic retinopathy. Glia 2010;58:1996-2004.

31. Barber AJ, Lieth E, Khin SA, Antonetti DA, Buchanan AG, Gardner TW. Neural apoptosis in the retina during experimental and human diabetes. Early onset and effect of insulin. J Clin Invest 1998;102:783-91.

32. Martin PM, Roon P, Van Ells TK, Ganapathy V, Smith SB. Death of retinal neurons in streptozotocin-induced diabetic mice. Invest Ophthalmol Vis Sci 2004;45:3330-6.

33. Kern TS, Barber AJ. Retinal ganglion cells in diabetes. J Physiol 2008;586(Pt 18):4401-8.

34. Palmowski AM, Sutter EE, Bearse MA Jr, Fung W. Mapping of retinal function in diabetic retinopathy using the multifocal electroretinogram. Invest Ophthalmol Vis Sci 1997;38:258696.

35. Lieth E, Gardner TW, Barber AJ, Antonetti DA; Penn State Retina Research Group. Retinal neurodegeneration: early pathology in diabetes. Clin Experiment Ophthalmol 2000;28:3-8.

36. Jackson GR, Scott IU, Quillen DA, Walter LE, Gardner TW. Inner retinal visual dysfunction is a sensitive marker of nonproliferative diabetic retinopathy. Br J Ophthalmol 2012;96: 699-703.

37. Trick GL, Burde RM, Gordon MO, Santiago JV, Kilo C. The relationship between hue discrimination and contrast sensitivity deficits in patients with diabetes mellitus. Ophthalmology 1988;95:693-8.

38. Masha A, Dinatale S, Allasia S, Martina V. Role of the decreased nitric oxide bioavailability in the vascular complications of diabetes mellitus. Curr Pharm Biotechnol 2011;12: 1354-63.

39. Kowluru RA, Engerman RL, Case GL, Kern TS. Retinal glutamate in diabetes and effect of antioxidants. Neurochem Int 2001;38:385-90.

40. Obrosova IG, Drel VR, Kumagai AK, Szabo C, Pacher P, Ste- vens MJ. Early diabetes-induced biochemical changes in the retina: comparison of rat and mouse models. Diabetologia 2006;49:2525-33.

41. Deng J, Wu DZ, Gao R. Detection of glutamate and gammaaminobutyric acid in vitreous of patients with proliferative diabetic retinopathy. Yan Ke Xue Bao 2000;16:199-202.

42. Ambati J, Chalam KV, Chawla DK, D'Angio CT, Guillet EG, Rose SJ, Vanderlinde RE, Ambati BK. Elevated gamma-aminobutyric acid, glutamate, and vascular endothelial growth factor levels in the vitreous of patients with proliferative diabetic retinopathy. Arch Ophthalmol 1997;115:1161-6.

43. Schlingemann RO, Witmer AN. Treatment of retinal diseases with VEGF antagonists. Prog Brain Res 2009;175:253-67.

44. Jardeleza MS, Miller JW. Review of anti-VEGF therapy in proliferative diabetic retinopathy. Semin Ophthalmol 2009;24:8792.

45. Yang Z, Mo X, Gong Q, Pan Q, Yang X, Cai W, Li C, Ma JX, He Y, Gao G. Critical effect of VEGF in the process of endothelial cell apoptosis induced by high glucose. Apoptosis 2008;13: 1331-43.

46. Bai Y, Ma JX, Guo J, Wang J, Zhu M, Chen Y, Le YZ. Muller cell-derived VEGF is a significant contributor to retinal neovascularization. J Pathol 2009;219:446-54.

47. Hammes HP, Federoff HJ, Brownlee M. Nerve growth factor prevents both neuroretinal programmed cell death and capillary pathology in experimental diabetes. Mol Med 1995;1:52734.

48. Steinle JJ, Granger HJ. Nerve growth factor regulates human choroidal, but not retinal, endothelial cell migration and proliferation. Auton Neurosci 2003;108:57-62.

49. Elshaer SL, Abdelsaid MA, Al-Azayzih A, Kumar P, Matragoon S, Nussbaum JJ, El-Remessy AB. Pronerve growth factor induces angiogenesis via activation of TrkA: possible role in proliferative diabetic retinopathy. J Diabetes Res 2013;2013: 432659.

50. de Gooyer TE, Stevenson KA, Humphries P, Simpson DA, Gardiner TA, Stitt AW. Retinopathy is reduced during experimental diabetes in a mouse model of outer retinal degeneration. Invest Ophthalmol Vis Sci 2006;47:5561-8.

51. Arden GB. The absence of diabetic retinopathy in patients with retinitis pigmentosa: implications for pathophysiology and possible treatment. Br J Ophthalmol 2001;85:366-70.

52. Arden GB, Gunduz MK, Kurtenbach A, Volker M, Zrenner E, Gunduz SB, Kamis U, Ozturk BT, Okudan S. A preliminary trial to determine whether prevention of dark adaptation af- 
fects the course of early diabetic retinopathy. Eye (Lond) 2010; 24:1149-55.

53. Arden GB, Jyothi S, Hogg CH, Lee YF, Sivaprasad S. Regression of early diabetic macular oedema is associated with prevention of dark adaptation. Eye (Lond) 2011;25:1546-54.

54. Du Y, Veenstra A, Palczewski K, Kern TS. Photoreceptor cells are major contributors to diabetes-induced oxidative stress and local inflammation in the retina. Proc Natl Acad Sci U S A 2013; 110:16586-91.
55. Tang J, Kern TS. Inflammation in diabetic retinopathy. Prog Retin Eye Res 2011;30:343-58.

56. Zheng L, Kern TS. Role of nitric oxide, superoxide, peroxynitrite and poly(ADP-ribose) polymerase in diabetic retinopathy. Front Biosci (Landmark Ed) 2009;14:3974-87.

57. Tang J, Du Y, Lee CA, Talahalli R, Eells JT, Kern TS. Low-intensity far-red light inhibits early lesions that contribute to diabetic retinopathy: in vivo and in vitro. Invest Ophthalmol Vis Sci 2013;54:3681-90. 